\title{
Toward sustainable energy usage in the power generation and construction sectors-a case study of Australia
}

\author{
Merched Azzi ${ }^{\text {a,* }}$, Hiep Duc ${ }^{\text {b }}$, Q.P. Ha ${ }^{c}$ \\ a CSIRO Energy Flagship, 11 Julius Avenue, North Ryde, 2113 NSW, Australia \\ ${ }^{\mathrm{b}}$ Office of Environment \& Heritage, NSW, PO Box 29, Lidcombe, 2141 NSW, Australia \\ c University of Technology Sydney, PO Box 123, Broadway, 2007 NSW, Australia
}

\section{A R T I C L E I N F O}

\section{Article history:}

Received 4 December 2014

Received in revised form 7 June 2015

Accepted 6 August 2015

Available online $\mathrm{xxxx}$

\section{Keywords:}

Future energy

Sustainable energy

Distributed generation

Post-combustion capture

Construction industry

Green star rating

Sustainable building

\begin{abstract}
A B S T R A C T
To be sustainable in energy usage in the future, there are two aspects that need to be considered: the energy supply or generation and the consumption side, including the closely linked construction and building industries which consume a large amount of energy. Essential requirements for energy efficiency are to produce less greenhouse gas emissions and to rely more on renewable energy sources for future sustainability. Policies for mitigation of the environment impact are having effects on both the supply and demand. While the former requires more alternate sources in smart grids and improved technologies for carbon capture and storage, the latter involves the reduction of energy wastes and greenhouse gas (GHG) emissions as prerequisites to green certification within the construction and building sector. Thus, access to sustainable, affordable, and secure energy is one of the major global strategic priorities to maintain and improve public health, sustain economic growth, and mitigate the effects of climate change. Toward this goal, many countries, including Australia, are investing in clean, efficient, reliable energy systems for a prosperous and environmentally sustainable future. Hence, exploring various options to ensure energy security by diversification of energy sources is an important step in meeting the future requirements and delivering clean energy to different industry sectors. This paper discusses options to manage the use of energy sources in the power generation and construction industries. Options for mitigation of environmental impact and for achievement of sustainable energy usage, such as building design with BIM, are discussed.
\end{abstract}

(C) 2015 Elsevier B.V. All rights reserved.

\section{Introduction}

As economies and populations are predicted to grow, the world demand for energy will increase. The US Energy Information Administration's (EIA's) "International Energy Outlook 2014" (IEO2014) [1] reported that world energy consumption will grow by $56 \%$ between 2010 and 2040 . Fossil fuels will continue to supply nearly $80 \%$ of world energy use through 2040. Ensuring the availability of clean, abundant, and affordable energy will play a key role in developing economic prosperity and enhanced environmental quality. It is now well accepted that emissions from fossil fuels combustion should be limited because of their contribution to local and regional pollution as well as their contribution to global climate change [2].

Most of power generation and other energy-intensive industries rely on coal, a key source of energy. However, moving toward a low-carbon economy requires the existence of such industries that are capable of using coal more efficiently and of reducing its environmental footprint. From the consumption point, efficiency in energy usage is important in reducing emissions and mitigating impact on local environment such as

\footnotetext{
* Corresponding author

E-mail address: merched.azzi@csiro.au (M. Azzi).
}

air quality. In this regard, energy savings are essential in the major energy-consuming industries such as construction, building, and mining, in order to address the ultimate goal of improving environmental sustainability.

Construction industry uses energy at different stages of the project development, including preparation of land use, excavation, foundations, prefabrication, cement and concrete, manufacturing and transportation of building materials, construction equipment during the process, and disposal of construction wastes. Such activities are also associated with the emission of different types of air pollutants to the atmosphere that contribute directly to the greenhouse effect. Investigation of available options to mitigate emission in this industry sector will promote environmental sustainability. For example, activities related to the cement industry contribute to around $5 \%$ of global emission of carbon dioxide $\left(\mathrm{CO}_{2}\right)$ [3]. Options to effectively manage the use of energy on construction sites can also help reduce carbon emissions from the site. Therefore, efficient measures need to be taken to save energy, reduce hazardous wastes, and control GHG emissions in order to transform construction gradually into a low-carbon and sustainable industry.

Building construction consumes $32 \%$ of the world's resources and hence consumes a significant amount of energy. Buildings also produce $40 \%$ of wastes going to landfill and $40 \%$ of air emissions. With the 
ever-increasing world population and given that more and more anthropogenic activities are taking place indoor, building services are consuming a large fraction of the total electricity. In fact, $8 \%$ of Australian GHG emission is produced by commercial buildings, according to the Green Building Council of Australia (GBCA) [4]. In the United States, buildings are responsible for almost half of all greenhouse gas emissions and they consume about three-quarters of all electricity generated by power plants [5]. Therefore, design and development of built infrastructure, highly efficient energy usage, and ecological adaptation not only reduce the impact on environment and save the running cost hence bringing economic benefits but also create a sense of well-being and health for building occupants, resulting in increased productivity in the long run. The demand for sustainable buildings is increasing worldwide and many companies are vying for business in the design and construction of green buildings.

More stringent environmental regulations in addition to the proposed limits on greenhouse gas emissions from fossil-fuelled power plants have played a key role in initiating new research opportunities to help meet these new targets [2]. Currently, efforts are being made by major research organizations to develop and demonstrate the availability of ultraclean, efficient, affordable fossil fuel energy technology that can be used to meet future requirements for energy production and use. If this technological success is achieved, it will be likely for coal and natural gas to remain the major energy sources for power generation and will continue to meet the growing energy demand because of their abundant supply and relatively low cost when compared to other energy sources.

Construction and mining sectors constitute an important link in the planning process for sustainability of energy usage, especially in countries with heavy economic reliance on the mining industry such as Australia. Automation and control technology hence play a key role in the contribution toward achieving future energy and environment sustainability.

Following the introduction, the following sections of this paper presents the carbon capture technology and discusses emission control options that can be applicable to the power generation and construction industries.

\section{Carbon capture technology}

Reduction of carbon emissions from anthropogenic activities is a complex challenge for all industries. Different options are being attempted to tackle this problem. One of the advanced options is the carbon capture and storage (CCS) option. The CCS technology has been developed for the purpose of curbing greenhouse gas emissions from industrial processes. The technology is based on (i) cleaning the flue gas stream then separating and capturing carbon dioxide $\left(\mathrm{CO}_{2}\right)$, (ii) compression and transport of $\mathrm{CO}_{2}$, and (iii) underground storage of $\mathrm{CO}_{2}$. The wide deployment of $\mathrm{CCS}$ will reduce $\mathrm{CO}_{2}$ emissions from industrial sources while ensuring that coal will remain as a relatively cheap option to power a sustainable economy.

Reducing $\mathrm{CO}_{2}$ emissions from coal-fired power plants would have a significant impact on reducing the effects of climate change. Carbon capture and sequestration is a potential option to keep fossil fuels in the electricity mix. Incorporating carbon capture technologies into coal-fired power plants will reduce GHG emissions from coal and emissions of other pollutants. Chemical absorption with amines is presently the only commercially available technology for industrial applications in that regard. $\mathrm{CO}_{2}$ is first captured from the exhaust gas stream in an absorption tower. The absorbed $\mathrm{CO}_{2}$ is then heated with steam to strip the $\mathrm{CO}_{2}$ from the amine solution. The regenerated amine is sent back to the absorber. The recovered $\mathrm{CO}_{2}$ is cooled, dried, and then compressed to a supercritical fluid. At this stage, the fluid can be piped to sequestration.

Post-combustion capture (PCC) of $\mathrm{CO}_{2}$ using amine solvent, as illustrated in Fig. 1 , is a readily available technology to capture $\mathrm{CO}_{2}$ from coal-fired power plants and from the cement industry in construction. The process would be retrofitted downstream of the cleaned flue gas. The aqueous amine solvent will undergo a reversible chemical reaction with $\mathrm{CO}_{2}$ and will selectively capture $\mathrm{CO}_{2}$ from the flue gas stream. Under elevated temperature, $\mathrm{CO}_{2}$ will be released and the lean solvent will be recycled back to absorb more $\mathrm{CO}_{2}$ from the flue gas stream of the power plant. The flue gas exiting the power plant to enter the PCC includes different compounds such as sulfur oxides $\left(\mathrm{SO}_{\mathrm{x}}\right)$, nitrogen oxides $\left(\mathrm{NO}_{\mathrm{x}}\right)$, oxygen $\left(\mathrm{O}_{2}\right)$, particulate matters, and other compounds. Some of these compounds interact with the solvent to produce different by-products which may affect the solvent performance. There is potential for selected by-products to leave the plant and undergo additional chemical reactions in the atmosphere. The full understanding of these chemical transformations is needed for plant operating approval where emissions from the plant should not exceed defined limits.

Over the last years, the Commonwealth Scientific and Industrial Research Organisation (CSIRO) in Australia has been engaged in improving the knowledge associated with the operation of PCC plants, development of new solvents to resist degradation, elucidating the chemistry of amines in the process and their fate in the atmosphere and acquiring information to carry out environmental assessment for future PCC deployment in Australia and other parts of the world.

The process flow sheet with various streams around $\mathrm{CO}_{2}$ absorber and stripper with their steady state flow rate, temperature, and pressure values is simulated by using Aspen-Plus software, typically for the $\mathrm{CO}_{2}$ capture plant during direct caustic wash.

It can be shown that cooling the absorber outlet gas and washing it with a large quantity of circulating demineralized water in the wash tower can minimize emissions of mono-ethanolamine (MEA) and its degradation products to the atmosphere [6]. In another study, it was also found that besides removing $\mathrm{CO}_{2}$ from the flue gas of coal-fired power stations using an amine-based solvent, the PCC technology can be used also to reduce the emissions of nitrogen dioxide $\left(\mathrm{NO}_{2}\right)$, particulate matter (PM), and sulfur dioxide $\left(\mathrm{SO}_{2}\right)$, leading consequently to improved air quality [7]. It is important to note that retro-fitting a PCC plant has the potential to impact both the traditional air pollutants in addition to providing a source of new pollutants based on emission and degradation products of MEA.

It is expected that regional air quality modeling systems, currently used to access the impact of source emissions of different speciation profiles on air pollution, will be applied in the near future to access the impact of PCC emission profiles on the formation of secondary air pollutants such as ozone and secondary organic aerosols (SOA). Joint research efforts have been carried out to develop an enhanced ozone and particle formation model to access the impact of different source emission profiles on air pollution in the Sydney basin and surrounding regions [8].

\section{Emissions from construction activities}

Construction activities are a multi-stage process that includes the design, construction, use, and demolition of building and infrastructure. Construction also includes indirect activities that encompass earthwork handling, extraction of various raw materials, energy-intensive processes associated with manufacturing, and delivery of the building materials.

The carbon footprint of the construction industry extends to the supply chains where the footprint of individual products is needed to identify carbon "hot spots" and to focus efforts on carbon reduction from the identified suppliers. There is room for improving the performance in the process or operational management. For example, it has been shown that emission of $\mathrm{CO}_{2}$ is increased while the engine of nonroad diesel construction equipment is idling [9].

Construction activities may have a certain environmental impact that extends from land use to emissions from energy use. The emissions commonly generated from the construction industry include exhaust 


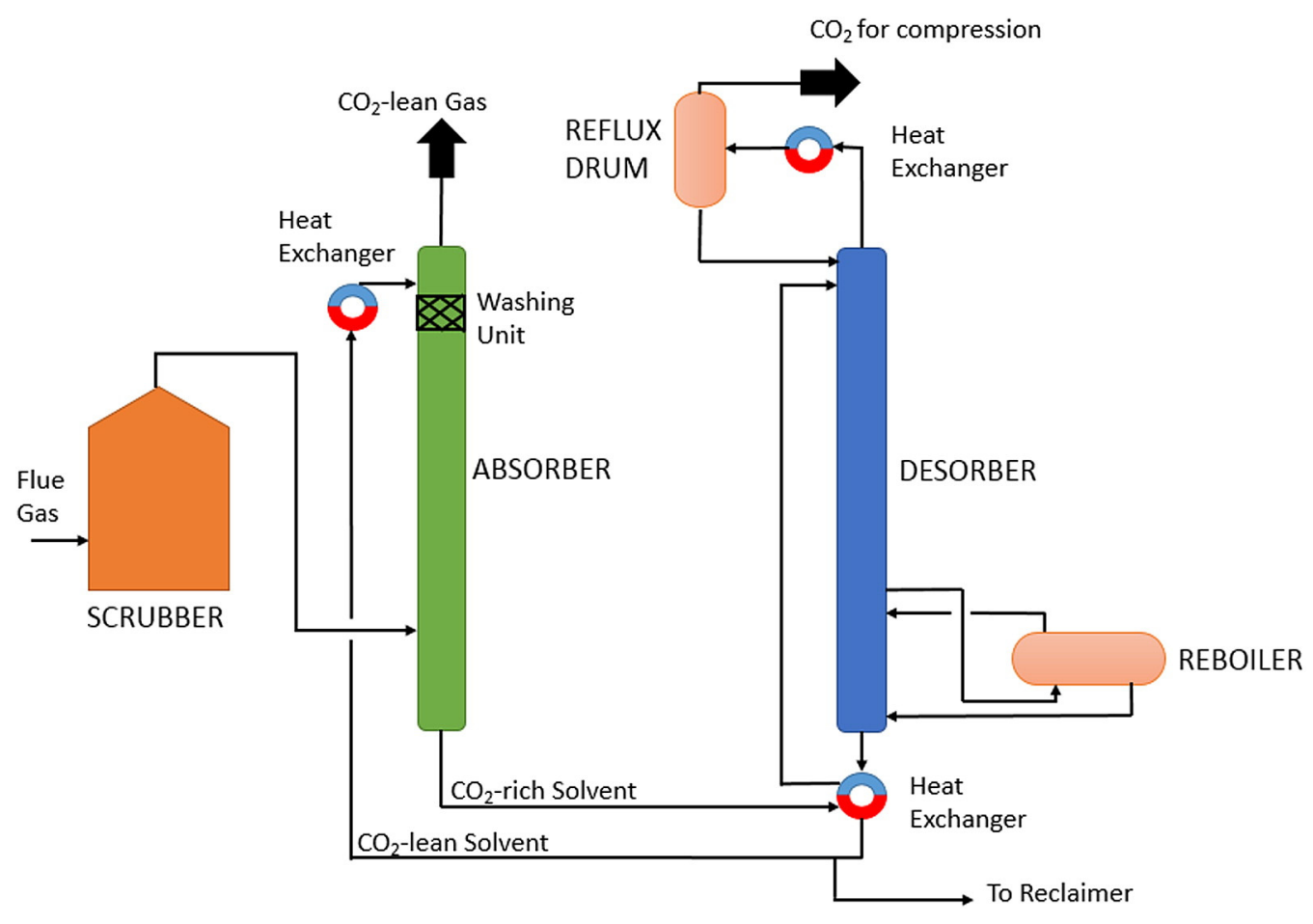

Fig. 1. Standard amine-based PCC process flow sheet.

emissions of $\mathrm{NO}_{\mathrm{x}}, \mathrm{PM}$, reactive organic compounds, hazards pollutants, carbon monoxide (CO), exhaust emissions of greenhouse gasses such as $\mathrm{CO}_{2}$, methane $\left(\mathrm{CH}_{4}\right)$, and nitrous oxide $\left(\mathrm{N}_{2} \mathrm{O}\right)$, direct emissions associated with dust from soil disturbance and demolition, and evaporative emissions from paving activity and coatings.

The location of proposed construction sites and their spatial extent are key factors in assessing local and regional environmental impacts. Sources of materials and waste disposal that may release methane in the future are also to be accounted in the environmental assessment. To improve social, economic, and environmental indicators of sustainable development, the life cycle assessment (LCS) methodology has been applied to optimize all construction aspects, from raw building materials to the whole building life cycle including the final disposal of building wastes [10]. Within the building sector, energy-intensive industries such as steel and cement are the main sources for energy use in addition to mobile sources of ecological concerns.

The steel industry has increasingly been aware of sustainable development to address directly the three basic indicators (economic, environmental, and societal) as well as via organizational governance and technical aspects [11]. In fact, technological development has enabled significant improvements in energy efficiency in the steelmaking process. Over the years, the amount of energy required to produce steel has been significantly reduced while increasing the entire life cycle of steel products with lighter, safer, more long-lasting and smarter structures in construction and built infrastructure applications. In Australia, an effective rating system has been applied to target the long-term sustainability and carbon neutrality in both buildings and infrastructure by reducing energy and emissions in the steel industry [12].

Together with steel, cement also contributes significantly to $\mathrm{CO}_{2}$ emissions, it is therefore important to investigate how the cement industry can reduce its carbon footprint. Associated with cement manufacturing are direct and indirect GHG emissions [13], whereby heating of limestone releases $\mathrm{CO}_{2}$ directly through calcination. This process accounts for about $50 \%$ of all emissions from the cement industry while kilns are usually heated by fossil fuels, producing around $40 \%$ of $\mathrm{CO}_{2}$ emissions [3]. Another $5-10 \%$ of $\mathrm{CO}_{2}$ emissions are indirectly produced by electricity used to power additional plant machinery and final transportation of cement.

A study carried out by the International Energy Agency [14] has identified different options to achieve a significant reduction of $\mathrm{CO}_{2}$ emissions from cement manufacturing by 2050. Possibilities are discussed on the use of alternative fuels such as natural gas and biomass fuels in lieu of combustible fuels, and improvement of energy efficiency. Blended cement replacing some of the limestone-based clinker with other materials, primarily from coal fly ash and blast furnace slag, can also decrease the level of emissions. Furthermore, the cement industry should investigate how to appropriately select and deploy the carbon capture technology. In this regard, $\mathrm{CO}_{2}$ can be captured by PCC, then compressed and transported for later usage or storage. In cement production, two streams of $\mathrm{CO}_{2}$ emissions, from fuel combustion and from limestone calcinations in the kiln, may require specific capture technologies due to the difference in the flue gas characteristics. The European Cement Research Academy has published a detailed study discussing the potential use of amine-based PCC to capture $\mathrm{CO}_{2}$ from the cement industry [15]. It concluded that PCC can be readily fitted to a cement plant despite some challenges related to pre-treating flue gas to manage the dust and $\mathrm{SO}_{\mathrm{x}}$ emissions as well as meeting additional heat requirements for the solvent process [16].

\section{Low-carbon electricity}

Construction and buildings remain the sector that consumes most of energy generated. Apart from improving the energy performance in this sector, there is an urgent need to explore practical options that can help promote the use of available energy resources to produce electricity as we move forward to a reliable and sustainable energy. In many countries, electricity generation from fossil-fuelled plants has been subject to stringent environmental regulations because of concerns about their effects on air, water quality and their contribution to GHG emissions [2]. Centralized large fossil fuels power plants and decentralized energy generation from renewable sources will present the new mix of electricity generation in Australia. This represents an attempt to shift from conventional centralized fossil fuels generation to more 
efficient emission-free or near zero emissions from a variety of energy sources. To this end, some questions need to be addressed.

\subsection{How well can we plan and implement sustainable energy systems?}

For centralized power plants, it is crucial to assess the use of highefficiency centralized large fossil-fuelled power plants equipped with emissions reduction technologies and potentially carbon capture systems. A successful sustainable centralized power generation system will be measured by meeting the following targets: increasing efficiency and significantly reducing emissions while guaranteeing cost-effectiveness.

\subsection{How to deploy sustainable decentralized power generation in} Australian urban areas?

Decentralized electricity generation will be produced from a variety of renewable sources including gas, solar radiation, biomass, and natural gas and wind. In contrast to conventional generation, decentralized generation consists of smaller scale generation sources interconnected to a utility's distribution grid. It is expected that the mix smart grid will exhibit a tremendous complexity manifested by its diversity, dynamic behavior, space, and power output. The anticipated energy system would have to ensure the security of supply under different operating modes and would be able to demonstrate safe and environmentally sound operation of the selected system.

\subsection{What environmental regulations and policies are needed?}

Thermal power plants are currently playing a major role in power generation. Incorporating a large fraction of electricity supply from other sources will require changes to many existing regulatory aspects and policies to take into account peculiarities of each source.

The investment in renewable energy sectors, such as solar and wind power generation, on one hand, is increasing rapidly around the world. On the other hand, policy to reduce greenhouse gas emission such as carbon trading schemes have already been applied in the European Union countries and is being considered or implemented in other countries. It is expected that such policies will have an impact on energy usage in major energy-consuming industries including the construction and buildings sector, whereby high energy efficiency and low environment impact are criteria for green certification.

\subsection{Decentralized power generation}

In decentralized energy generation, multiple stationary power generators are installed close to end-users to supply part of the electricity demand. The approach is referred to as distributed generation (DG), which shifts the design and layout of power generation and distribution systems to reduce pollution by increasing efficiency and promoting the inclusion of renewable energy sources. The DG model operates on a more efficient and smaller scale than traditional systems. The DG configuration does not require transmission lines, as sources are connected directly to the lower-voltage distribution network.

Advanced technological achievements in addition to more stringent environmental regulations have resulted in an increasing interest in the deployment of DG systems. Nevertheless, the integration of different DG energy sources with existing centralized power plants requires extensive management to secure the electricity supply to customers. The distributed generator technologies that are likely to be implemented in major Australian cities include but are not limited to natural gas-fired combustion turbines, natural gas-fired reciprocating internal combustion engines, natural gas-fired micro-turbines, solar photovoltaics, and wind turbines. The mix may also include diesel and petroleum distillate fuelled units that can be used as back-up generators. Economic, regulatory, and environmental requirements will play a major role in the selection of the mix of DG technologies to be installed in any particular region in the world.

It is expected that many of the DG technologies that might be adopted within urban areas would result in displaced emissions and would also experience some degradation in energy efficiency, consequently, degrading pollutant emission performance. A systematic methodology for the development of realistic DG deployment scenarios is needed. This methodology will take into consideration all characteristics and factors needed to minimize the local concentration pollutant profiles expected from operating these generators with the least environmental and health impacts.

To assess the environmental benefits of DG in an air-shed, it is important to consider the variety of technologies employed, total percentage of DG in the region, emission profiles, and the use of an appropriate dispersion model in order to quantify how the deployment of the new energy mix can improve air quality in terms of increasing efficiency and reducing pollutant emissions. As reported in [17] on air quality impact considering a scenario where energy generation paradigm moves from large centralized energy generation (such as coal-fired power station) to widespread deployment of small power units located close to the point of use in New South Wales, Australia, emissions of $\mathrm{NO}_{\mathrm{x}}$, volatile organic compounds (VOC), and CO associated with the DG deployment would likely cause a small increase in domain-wide mortality (changing by less than $0.01 \%$ ). The DG deployment contributed an additional $1 \%$ to the existing pollution burden in the region. This study demonstrates how decision makers and stakeholders can plan for future introduction of combustion-based DG systems using modeling tools and select optimal approaches to meet the growing electricity demands while minimizing health risks.

\subsection{Centralized power generation}

Coal remains the largest provider of electricity generation. Over 75\% of Australia's electricity is still generated by coal-fired power plants. The traditional Australian electrical power system model consists of centrally located power plants, transmission lines, and distribution networks. While renewable energy sources have started to contribute to the production of electricity in Australia, centralized coal-fired power plants located typically in remote areas will continue to be the major source of power generation. These plants are known for their low efficiency, high emissions, and large land disturbance. The challenges to the continued use of coal are related to its environmental impact and health concerns.

Combustion emissions depend on the fossil fuels used and the type of power plant run by the fuels. Pollutants generated can include $\mathrm{NO}_{\mathrm{x}}$, $\mathrm{SO}_{\mathrm{x}}, \mathrm{PM}$, and $\mathrm{CO}_{2}$. There are other compounds expected to be produced from incomplete combustion of fuels such as VOC, unburned carbon, and trace elements. It is recognized that natural gas is the least polluter of all fossil fuels as it results mainly in emissions of $\mathrm{NO}_{\mathrm{x}}, \mathrm{CO}_{2}$, and very small amounts of other pollutants.

Over the last two decades, regulatory agencies have forced utility companies to meet more stringent emission standards and improve efficiency. Many of the proposed solutions and policies to reduce emissions from these plants were achieved by technological improvements. The installation of pollution control and prevention equipment in order to reduce the amount of pollutants released to the atmosphere and meet environmental guidelines has helped the industry to operate under regulated limits of emissions.

The average efficiency of coal-fired power plants varies from under $30 \%$ to $45 \%$ net calorific value. These differences arise from diverse factors including age of the plant, steam conditions, and coal quality. Over $50 \%$ of operating plants use a subcritical technology. Pulverized coal combustion in supercritical, ultra-supercritical steam cycle, and integrated coal gasification combined gas turbine-steam cycle (IGCC) technologies are proven efficient technologies which produce fewer GHG emissions per unit of power. These plants are being used in Asia, 
Europe, and in the US. They provide higher energy efficiency for power generation from coal and with less emission. Different pollution control technologies such as the PCC mentioned above are installed on modern coal plants to reduce emissions of atmospheric pollutants.

New sources of power generation have been introduced and pollution mitigation devices installed, but air quality impacts from electricity production still exist. Because of this, conventional power systems have remained largely unchanged, with the exception of technological upgrades toward environmental sustainability.

\subsection{Environmental regulations and policies}

Ecological concerns about the impacts of fossil fuel production, processing, and utilization have pushed authorities to introduce regulations to reduce smog formation, air pollution, acid rain, and other air pollution compounds. In addition, more recently, the reduction of GHG emissions has been the main focus because of its relationship with climate change concerns.

As part of the recent and future international agreements and protocols on action plans to mitigate the effect of climate change, each country is required to reduce the dependence of energy usage on fossil fuels which together with deforestation remain the major sources of $\mathrm{CO}_{2}$ emissions, identified as responsible for global warming and climate change. Commitments are also expected with regards to diversification of energy sources including the increasing of the supply of renewable energy and the improvement of technologies involved with the efficient use of fossil fuels. In this direction, policies are being developed and implemented so that the emission reduction target can be achieved.

Environmental policies and regulations are not the only mandates facing the electric utility industry. Other new stringent regulations related to coal ash management, disposal, and water discharge are being promulgated. Compliance with these new regulations will require new control devices and investments. Coal power utilities will confront unprecedented funding and management challenges to meet these new regulations. The installation of different pollution control devices to meet existing and future environmental guidelines requires a cumulative assessment to avoid any counterproductive effects of such devices.

Decreasing reliance on fossil fuels by incorporating different sources from renewable energy and natural gas will require different environmental regulations and policies to those designated for the existing thermal power plants. Regulatory considerations for future energy mix technologies may include the upcoming cost of carbon and increased control requirements for emissions.

In addition to environmental regulation and government energy policies, the major industrial and commercial businesses in the construction and building sector are encouraged to adopt a broad range of measures to deliver long-term environmental improvement. In Australia, GBCA has developed a comprehensive, national, voluntary environmental rating scheme, called the Green Star, to evaluate environmental performance of buildings. With this adoption by the industry, Green Star is expected to transform the Australia built environment. Currently, more than 7.2 million square meter building space has been certified and a further 8 million is registered with Green Star [4]. The Green Star performance rating is bringing a significant difference to the construction and buildings industry in Australia.

\section{Low-carbon construction, mining, and buildings}

\subsection{Energy and emissions}

The construction and mining sectors are major consumers of fossil fuel. In some areas, such as the coal mining areas of the Upper Hunter region in New South Wales, Australia, in addition to the dust and PM pollution due to open cut mining, the emission of greenhouse and pollutant gasses from construction and mining equipment is of much concern for the government and residents of the surrounding areas.
Legislation and regulation have been introduced recently to limit the emission of motor vehicles in general and the emission from mining vehicles and equipment in particular. In this respect, the Australian government is considering the option of removing current diesel fuel subsidies or tax deduction for the mining industry to force mining companies to invest in using alternative sources of energy or adopting advanced technologies for energy usage with less emission.

Dust from construction activities, steel structures, and concrete work are currently under regulation with strict license conditions, compliant with stringent policies. Construction equipment is required to use lowsulfur fuels as well as advanced catalysts to achieve low particulate emission standards. Efficient energy usage is also a new trend in all aspects of the construction industry including buildings and building services. In the current competitive environment, business and enterprise are seeking to become cost-effective and reduce wastes, whereby energy usage is the area where such improvements could be achieved. A recent study in Korea showed that there is a high potential of achieving substantial reduction of GHG emission from onsite equipment usage in road construction if appropriate operational practice and management is put in place, such as proper selection of equipment and its components to deal with specific site conditions [18]. This is reinforced by another study in the US which shows that when environmental aspects of carbon emissions and diesel exhaust emissions are considered in the operational planning stage of a construction project, the project integrated value, which includes schedule, cost, and environmental impact, is increased [19].

\subsection{BIM and sustainability}

Buildings account for a large percentage of energy consumption and of $\mathrm{CO}_{2}$ emissions. With urban expansion, environmental concerns and energy costs are also rising. Sustainable design allows architects and engineers for realization of the practice designing, constructing, and operating new buildings with the ultimate goal of minimizing their environmental impact. To this end, an emerging common software called Building Information Modeling (BIM) is being well-adopted, which has embraced over the years IT-based tools to enable digital prototypes of buildings from all aspects from physical and operating characteristics, such as materials, site description, energy, lighting, to thermal services, heating ventilating air-conditioning (HVAC), and fabrication requirements. The energy performance of a building can be incorporated in BIM where all materials used and the entire life cycle of the building can be designed and assessed based on energy usage in its construction and its operation to support energy efficient building design, operation, and retrofit [20]. Incorporating these considerations into the early stages of architectural design is important that architectural and engineering firms are now using the same BIM tools for building design, and a number of sustainability concerns can be tackled throughout the entire construction process from design inception to facilities management and life cycle analysis [21]. These can further contribute to better scheduling of construction tasks, personnel and equipment, and management quality which result not only in improved economic return from design validation [22] but also in the ability to adapt and comply with the future regulatory framework on greenhouse or other pollutant emissions to mitigate their effects on environment and climate change.

Similar to energy rating of household appliances such as Energy Star, rating systems for environmental performance of buildings are now widespread in many countries. These include the Leadership in Energy and Environmental Design (LEED) [23] in the US, Canada, India; the German Sustainable Building Council (DGNB) certification in Germany; or the Building Research Establishment Environmental Assessment Method (BREAM) in the UK [24]. Not only are newly green buildings with environmental consideration constructed but also refurbishment of old buildings to become green buildings is an increasing trend in the building sector. Indeed, many currently used BIM systems are now 
incorporating green building rating to achieve LEED or Green Star certification. This covers a number of performance aspects such as low energy usage in building, energy modeling, sustainable materials, water harvesting, building orientation, and lighting analysis.

\section{Conclusion}

In order to achieve a sustainable future, to reduce the environmental impact, and to mitigate the effect of climate change, energy production and consumption have to evolve and adapt to the new regulatory and policy framework, particularly in construction and building sectors, which account for a large percentage of energy generated. Low-carbon energy production and reduced GHG emission is the means to mitigate the effect of climate change and the trend in power generation development globally.

In the construction and mining industries, the trend to achieve energy and environment sustainability by using low-emission fuel and less emission technology is accelerating. Legislation and regulation to reduce GHG and particles emissions from the construction and mining industries have recently been introduced in some countries, such as Australia. The construction and mining industries have responded to these requirements to reduce emissions correspondingly by adopting cleaner fuels with low pollutant emission from improved catalyst converters. Evolving environmental regulation and various policy initiatives are also being tried out and formulated to target low carbon electricity emission. In Australia, the local and state governments have commissioned studies into various ideas and projects, such as DG, CCS, and PCC. It is expected that the evolution in low-carbon power generation technology will provide a sustainable and long-term security in the supply of energy with less impact on air pollution and climate change. As one of the largest greenhouse emission producers, the construction, building, and mining sectors are also adapting quickly to the new operating environment with energy performance rating scheme. The green building concept is currently being incorporated into the BIM-assisted architectural and engineering design process to achieve sustainable design and environmental performance rating in a number of projects in Australia and many countries. It is expected that the BIM-assisted design process will fully take into account the guidance and framework of reducing pollutant emission for the entire life cycle from design, construction, and operation so that it can meet expected future policies of low-carbon energy and less emission in many industries to mitigate the effect on climate change and the environment.

\section{References}

[1] International Energy outlook 2014, DOE/EIA-0484(2014)September 2014

[2] USEPA 2014, http://www2.epa.gov/carbon-pollution-standards/clean-power-planproposed-rule.

[3] D. Huntzinger, T. Eatmon, A life-cycle assessment of Portland cement manufacturing: comparing the traditional process with alternative technologies, J. Clean. Prod. 17 (2009) 668-675

[4] Green Building Council of Australia, http://www.gbca.org.au/.

[5] AIA Architects and Climate Change, http://www.aia.org/aiaucmp/groups/aia/documents/pdf/aias077675.pdf.

[6] D. Thong, N. Dave, P. Feron, M. Azzi, Process Modelling for Amine-based Post Combustion Capture Plant, Final report for the Australian National Low Emissions Coal Research and Development-Activity 32012.

[7] C. Emmerson, M. Cope, S. White, D. Angove, M. Azzi, 3D Dispersion Modelling of Monoethanolamine (MEA) from a Hypothetical Power Station, Final report for the Australian National Low Emissions Coal Research and Development-Activity 42013.

[8] H. Wahid, Q. Ha, H. Duc, M. Azzi, Neural network-based meta-modelling approach for estimating spatial distribution of air pollutant levels, Appl. Soft Comput. 13 (2013) 4087-4096

[9] P. Lewis, M. Leming, W. Rasdorf, Impact of engine idling on fuel use and $\mathrm{CO} 2$ emissions of non-road diesel construction equipment, J. Manag. Eng. 28 (2) (2012) 31-38.

[10] O. Ortiz, F. Castells, G. Sonnemann, Sustainability in the construction industry: a review of recent developments based on LCA, Constr. Build. Mater. 23 (2009) 28-39.

[11] R. Singh, H. Murty, S. Gupta, A. Dikshit, Development of composite sustainability performance index for steel industry, Ecol. Indic. 3 (2007) 565-588.

[12] http://steel.org.au/key-issues/sustainability.

[13] M. Waris, M. Lew, M. Khamidi, A. Idrus, Reducing the greenhouse gas emissions from onsite mechanised construction, Aust. J. Basic Appl. Sci. 8 (2014) 391-398.

14] Cement technology roadmap 2009 - Carbon emissions reductions up to 2050 $\mathrm{OECD} /$ International Energy Agency and the World Business Council for Sustainable Development, 2009, ISBN 978-3-940388-47-6.

[15] European Cement Research Academy, ECRA CCS Project - Report on Phase III Technical Report TR-ECRA-119/2012, 2012.

[16] Q. Zhu, $\mathrm{CO}_{2}$ abatement in the cement industry, IEA Clean Coal, June 2011.

[17] M. Azzi, M. Cope, M. Rae, W. Lilley, L. Reedman, An Assessment of the Air Quality Outcomes of a Distributed Generation Deployment into the Sydney Airshed, NSW Environmental Trust 2008/RD/0011. , CSIRO, 2011.

[18] B. Kim, H. Lee, H. Park, H. Kim, Greenhouse gas emissions from onsite equipment usage in road construction, J. Constr. Eng. Manag. 138 (8) (2012) 982-990.

[19] C.R. Ahn, S.H. Lee, Importance of operational efficiency to achieve energy efficiency and exhaust emission reduction of construction operations, J. Constr. Eng. Manag. 139 (4) (2013) 404-413.

[20] T. Crosbie, N. Dawood, S. Dawood, Improving the energy performance of the built environment: the potential of virtual collaborative life cycle tools, Autom. Constr. 20 (2011) 205-215.

[21] A. Shulueter, F. Thesseling, Building information model based energy/exergy performance assessment in early design stages, Autom. Constr. 18 (2009) 153-163.

[22] G. Lee, H. Park, J. Won, D3 city project-economic impact of BIM-assisted design validation, Autom. Constr. 22 (2012) 577-586.

[23] S. Azhar, W. Carlton, D. Olsen, I. Ahmad, Building information modelling for sustainable design and LEED rating analysis, Autom. Constr. 20 (2011) 217-224.

[24] L. Shweber, The effect of BREEAM on clients and construction professionals, Build. Res. Inf. (March 2013) 37-41. 